\author{
Tadeusz CHWALCZUK ${ }^{1}$ \\ PaweH TWARDOWSKI ${ }^{2}$ \\ Piotr KIERUJ ${ }^{3}$ \\ Piotr SZABLEWSKI ${ }^{4}$
}

\title{
DOKŁADNE TOCZENIE STOPU INCONEL 718 OSTRZAMI Z CBN
}

\begin{abstract}
Prezentowane badania dotyczą toczenia stopu Inconel 718 ostrzami z CBN w warunkach skrawania konwencjonalnego oraz wspomaganego laserowo. Przedstawiono wpływ prędkości skrawania na wybrane wartości parametrów chropowatości powierzchni. Dokonano optymalizacji parametrów technologicznych ze względu na minimalizację wartości wyjściowych.
\end{abstract}

Słowa kluczowe: toczenie, Inconel 718, CBN, chropowatość powierzchni obrobionej

\section{Wprowadzenie}

Kształtowanie struktury geometrycznej powierzchni (SGP) stopów mających zastosowanie $\mathrm{w}$ przemyśle lotniczym stanowi duże wyzwanie techniczne, m.in. ze względu na dobór strategii i narzędzi skrawających [2] czy też właściwości samego materiału obrabianego [3,6]. Stopy takie jak Inconel 718 mają tendencję do tworzenia narostów i wykruszeń na powierzchni obrobionej, które znacząco obniżają jakość SGP. Badania prowadzone przez wiele ośrodków skupiają się na takich rozwiązaniach, jak podawanie cieczy chłodząco-smarujących pod wysokim ciśnieniem, indukcyjne podgrzewanie elementu przed obróbką, czy też laserowe wspomaganie skrawania $[1,10]$. Laserowe wspomaganie skrawania jest jednym z niekonwencjonalnych sposobów obróbki umożliwiających efektywne kształtowanie trudno skrawalnych stopów [9, 10]. Zastosowanie dodatkowego źródła energii w postaci wiązki laserowej w trakcie skrawania przynosi znaczące efekty technologiczne i ekonomiczne, co zostało opisane m.in.

\footnotetext{
1 Tadeusz Chwalczuk, Politechnika Poznańska, e-mail: tadeusz.chwalczuk@put.poznan.pl

${ }^{2}$ Autor do korespondencji/corresponding author: Paweł Twardowski, Politechnika Poznańska, ul. Piotrowo 3, 60-965 Poznań, tel.: +48 6166528 51, e-mail: pawel.twardowski@ put.poznan.pl

${ }^{3}$ Piotr Kieruj, Politechnika Poznańska, e-mail: piotr.a.kieruj@ doctorate.put.poznan.pl

${ }^{4}$ Piotr Szablewski, Pratt\&Whitney Kalisz/PWSZ Kalisz, e-mail: piotr.szablewski@ pwk.com.pl
} 
w pracach $[3,8]$. Zniwelowane zostało również zjawisko anomalii powierzchni w zakresie małych posuwów $f<0,1 \mathrm{~mm} / \mathrm{obr}$.

Ciekawym obszarem badawczym, ciągle nieprzynoszącym zadowalających efektów technologicznych, jest laserowe wspomaganie toczenia w zakresie prędkości skrawania powyżej $300 \mathrm{~m} / \mathrm{min}[1,5,11]$. Obróbka przy takich prędkościach staje się nie tylko trudna ze względu na konieczność zachowania warunków cieplnych wspomagania laserowego, zapewniających efekt zmiękczania, ale też z uwagi na możliwość zastosowania różnych materiałów narzędziowych pracujących w podwyższonych temperaturach bez obecności cieczy chłodząco-smarującej. Problem ten staje się szczególnie istotny podczas obróbki materiałów, takich jak Inconel 718. Ponadto nie spotyka się w raportach i opracowaniach badawczych informacji o zastosowaniu laserowego wspomagania obróbki dla różnych odmian kinematycznych procesu, np. toczenia poprzecznego.

Celem przedstawionej pracy jest porównanie efektów laserowego wspomagania obróbki (LAM) dla różnych strategii procesu sekwencyjnego oraz ciągłego, podczas toczenia poprzecznego ostrzami CBN w zakresie prędkości skrawania od $v_{c}=250$ do $v_{c}=500 \mathrm{~m} / \mathrm{min}$.

\section{Zakres, warunki i technika badań}

Toczenie poprzeczne powierzchni zewnętrznych przeprowadzono na tokarce CTX 310 ECOLINE. Materiałem obrabianym był nadstop niklu Inconel 718 (AMS 5662) skrawany przy zmiennych wartościach $v_{c}[\mathrm{~m} / \mathrm{min}]$ wynikających z zastosowania stałej prędkości obrotowej $n=1180 \mathrm{obr}$./min, przy zastosowaniu różnych sposobów wspomagania laserowego.

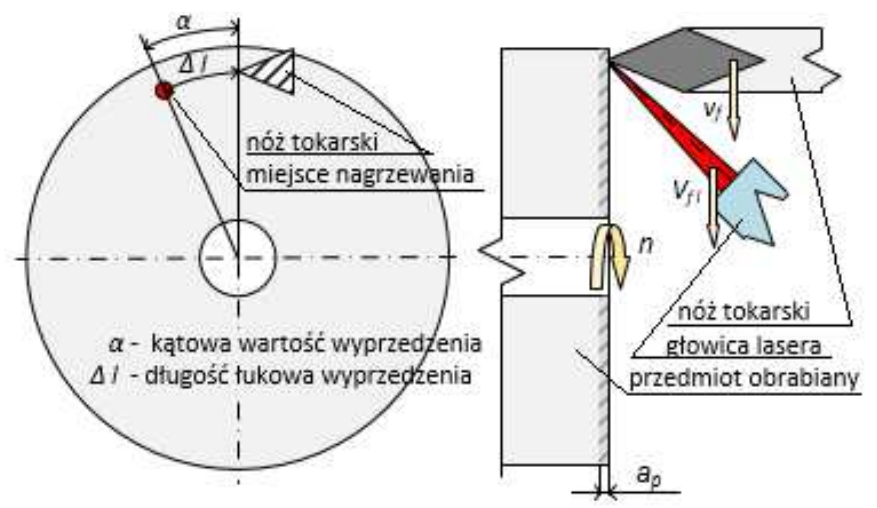

Rys. 1. Schemat kinematyczny toczenia poprzecznego w warunkach wspomagania z zachowaniem stałej prędkości obrotowej $n$ oraz gęstości energii $G E$

Fig. 1. Kinematic scheme of facing with laser assisted turning at a constant value of rotation speed $n$ and energy density $G E$ 
Przyjęto stałe wartości posuwu $f=0,08 \mathrm{~mm} /$ obr. oraz głębokości skrawania $a_{p}=0,15 \mathrm{~mm}$. Nagrzewano za pomocą lasera półprzewodnikowego TruDiode 3004, przy zachowaniu stałej wielkości średnicy wiązki na powierzchni materiału $d_{l}=1,2 \mathrm{~mm}$ oraz powłoki absorbującej typu gwash. Zmienność prędkości skrawania, tym samym prędkości nagrzewania, wymagała zachowania stałych parametrów nagrzewania w trakcie prób. Przyjęto stałą odległość łukową $\Delta l$ między miejscem nagrzewania i skrawania niezależnie od średnicy, zgodnie ze schematem przedstawionym na rys. 1 .

Jako parametr stały przyjęto gęstość energii $G E\left[\mathrm{~J} / \mathrm{mm}^{2}\right]$. Ze względu na duże różnice między średnią początkową oraz końcową, w celu zachowania stałej wartości $G E$ wymagane było zachowanie zmiennej mocy lasera na obrabianej średnicy (tab. 1). Zmienność opisanych parametrów zobrazowano na rys. 2. Zastosowano płytki skrawające DCGW 11T308 HS-NU2 firmy Sumiomo. Materiał narzędziowy to regularny azotek boru o oznaczeniu BN7500. Zalecane prędkości skrawania dla tego materiału narzędziowego $v_{c}=100 \div 300 \mathrm{~m} / \mathrm{min}$, $f=0,05 \div 0,15 \mathrm{~m} / \mathrm{min}$ dla obróbki dokładnej. Zastosowano oprawkę DCLNL $2020 \mathrm{~K} 12$.

Rys. 2. Graficzne porównanie parametrów zmiennych nagrzewania i toczenia poprzecznego w celu zachowania stałej wartości gęstości energii nagrzewania wiązką lasera

Fig. 2. Graphical comparison of heating and facing parameters to keep a constant value of energy density of laser beam heating

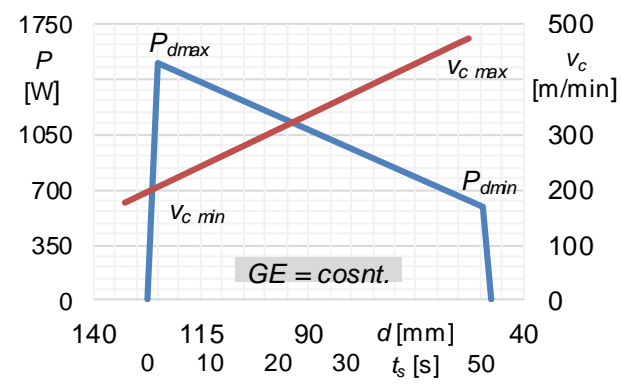

Chropowatość powierzchni rejestrowano na profilografometrze Hommel Tester T500. Mierzono parametry chropowatości według ISO 4288 na odcinku pomiarowym $L t=4,80 \mathrm{~mm}$. Analizę statyczną wyników przeprowadzono, stosując poziom istotności dla poszczególnych testów $\alpha=0,05$. Wykresy przebiegu zmienności to funkcje regresji w postaci wielomianu drugiego stopnia. Poszczególne próby porównano, stosując metodę graficznej analizy wartości średnich (ANOM), której szczegóły są opisane w pracy [7]. Słupki błędów na poszczególnych wykresach to odchylenia standardowe z próby.

Ograniczenia prezentowanej metody oceny parametrów chropowatości podczas toczenia poprzecznego są obarczone błędem związanym ze zmiennym zużyciem ostrza skrawającego, wpływającego na strukturę geometryczną powierzchni (SGP) obrobionej. W celu zmniejszenia tego rodzaju błędu prezentowane wyniki dotyczą okresu stabilnego zużycia w przedziale wartości wskaźnika $V B_{c}=0,05-0,15 \mathrm{~mm}$. 


\section{Analiza wyników badań}

Próby toczenia przeprowadzono w kolejności przedstawionej w tab. 1. Analizę parametrów SGP przeprowadzono po podziale średnicy toczonej na 9 równych odcinków. Tym samym 9 odcinków pomiarowych zwartych zostało w promieniu wałka.

Tabela 1. Oznaczenia oraz wartości parametrów nagrzewania dla poszczególnych prób; konw. - toczenie konwencjonalne; SLAM - toczenie ze wspomaganiem sekwencyjnym; CALM - toczenie z nagrzewaniem ciągłym

Table 1. Codes and parameters values for heating conditions of individual tests; konw. (conv.) - conventional turning; SLAM - sequential laser assisted machining; CLAM - continuous laser-assisted machining

\begin{tabular}{|l|c|c|c|}
\hline \multicolumn{1}{|c|}{ Symbol próby } & $\begin{array}{c}G E \\
{\left[\mathrm{~J} / \mathrm{mm}^{2}\right]}\end{array}$ & $\begin{array}{c}G P \\
{\left[\mathrm{~W} / \mathrm{cm}^{2}\right]}\end{array}$ & $\begin{array}{c}P \\
{[\mathrm{~W}]}\end{array}$ \\
\hline (0) konw. & - & - & - \\
\hline (1) SLAM & 0,194 & & 5 \\
\cline { 1 - 2 } (2) SLAM 2 & 0,940 & \multirow{2}{*}{$5-13$} & $593-1500$ \\
\cline { 1 - 2 } (3) CLAM & 0,194 & & \\
\hline
\end{tabular}

Podstawowym celem pracy jest porównanie parametrów struktury geometrycznej powierzchni po różnych sposobach wspomagania laserowego w szerokim zakresie prędkości skrawania. Na rysunku 3a przedstawiono przebiegi wartości parametrów $R a$ dla analizowanego zakresu prędkości skrawania. Toczenie konwencjonalne charakteryzowało się dużym rozrzutem wyników o wartościach średnich $R a$ większych niż uzyskiwane w warunkach wspomagania laserowego. Porównując wpływ wspomagania laserowego w wyniku przetopienia warstwy wierzchniej (SLAM) oraz przez cieplne zmiękczenie warstwy skrawanej (CLAM), można zauważyć, że każde warunki nagrzewania mają istotny wpływ na kształtowaną SGP. W przypadku wspomagania sekwencyjnego o dużej gęstości mocy SLAM 2 oraz wspomagania ciągłego CLAM średnie wartości parametrów chropowatości $R a$ nie przekraczały $0,30 \mu \mathrm{m}$ w całym zakresie badanych prędkości skrawania.

Sekwencyjne wspomaganie przy mniejszym udziale gęstości $G E$ cechuje się mniejszym zakresem wartości $v_{c}$, dla których $R a<0,30 \mu \mathrm{m}$. Mniejszy wydatek energetyczny podczas nagrzewania wiąże się z oszczędnością, przy jedoczesnym zadowalającym efekcie technologicznym. Warto zauważyć, że uzyskane w tej pracy parametry chropowatości $R a$ są niższe niż w inny pracach dotyczących laserowego wspomagania skrawania stopu Inconel $718[6,11]$.

$\mathrm{Na}$ rysunku $3 \mathrm{~b}$ przedstawiono wartości parametru $R s k$, istotnego między innymi ze względu na możliwości prognozowania takich właściwości eksploatacyjnych powierzchni, jak tarcie i zużycie, smarowanie i korozja zmęczeniowa [4]. 

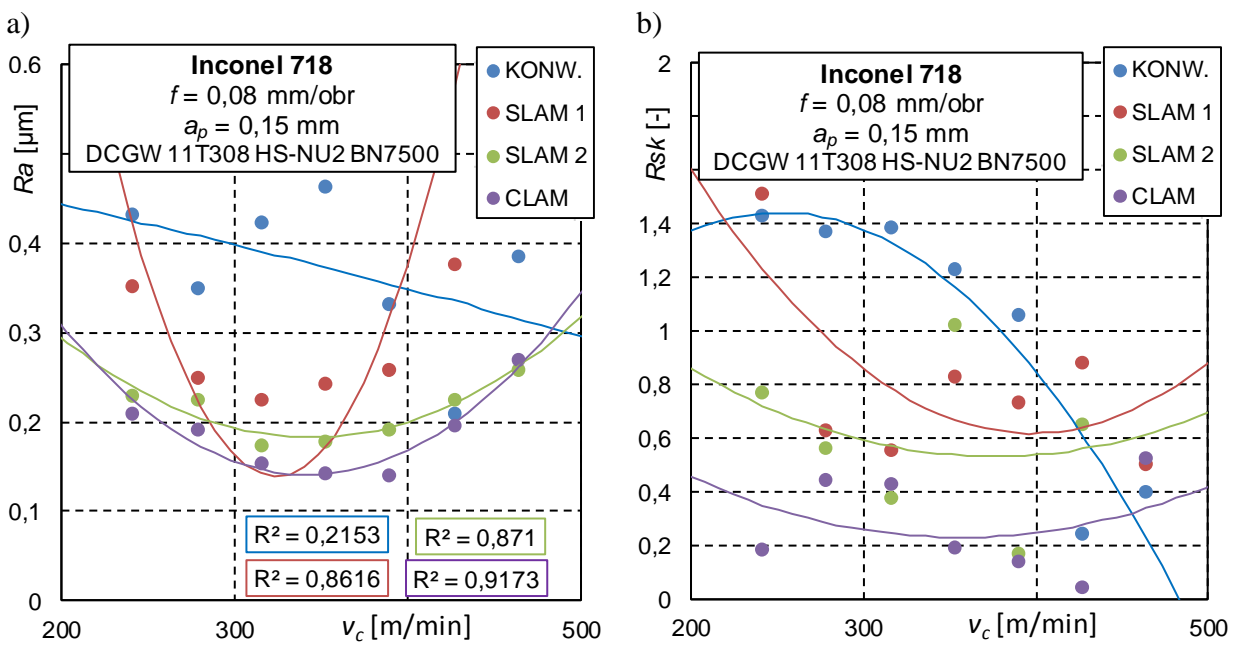

Rys. 3. Porównanie przebiegów parametru chropowatości a) $R a$ oraz b) $R s k$ w funkcji prędkości skrawania przy różnych sposobach skrawania

Fig. 3. Comparison of changes of a) $R a$ and b) $R s k$ roughness parameters as a function of cutting speed for various cutting methods

Skośność chropowatości mieszcząca się w przedziale $R s k>0$ świadczy o wierzchołkowym charakterze profilu, typowym dla procesu toczenia. Dla każdego $\mathrm{z}$ analizowanych sposobów toczenia, zarówno konwencjonalnego, jak i LAM, wartości były większe niż 0 . Najmniejszą zarejestrowaną wartość $R s k$ uzyskano dla CLAM przy prędkości $v_{c}=430 \mathrm{~m} / \mathrm{min}$. Zbliżenie parametru skośności profilu chropowatości do 0 może świadczyć o zaburzeniu w SGP oraz plastycznym odkształceniu górnej części profilu chropowatości, tzw. anomalii powierzchni obserwowanych, zwłaszcza w zakresie poniżej posuwu $f<0,1$ $\mathrm{mm} / \mathrm{obr}$. [3, 6].

W zakresie prędkości skrawania od $v_{c}=280 \mathrm{~m} / \mathrm{min}$ do $v_{c}=390 \mathrm{~m} / \mathrm{min}$ wartości parametrów amplitudowych chropowatości mogą wykazywać podobieństwo. W celu weryfikacji tej hipotezy przeprowadzono porównawczą analizę graficzną wartości średnich (ANOM). W porównaniu i optymalizacji uwzględniano jedynie toczenia ze wspomaganiem laserowym ze względu na uzyskanie mniejszych wartości parametrów niż zarejestrowane dla toczenia konwencjonalnego.

Wykresy przedstawione na rys. 4 dotyczące różnych sposobów skrawania oraz prędkości wykazują, że statystycznie wszystkie odmiany wspomagania laserowego się różnią. Żaden z pomiarów nie zawierał się w przedziale DLD-GLD wyznaczonym dla każdej wartości $v_{c}$. Najmniejsze wartości parametru $R z$ chropowatości zarejestrowano dla wspomagania ciągłego, czyli cieplnego zmiękczenia warstwy skrawanej z równoczesnym skrawaniem. W zakresie prędkości 

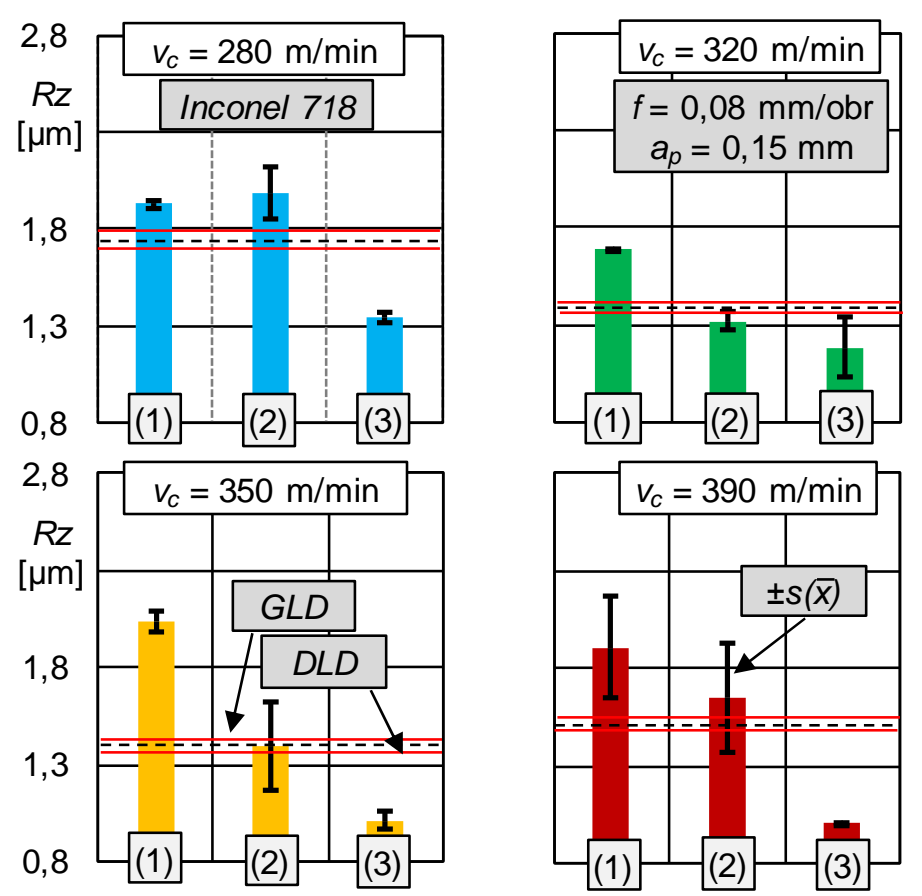

Rys. 4. Porównanie wartości parametru $R z$ dla laserowego wspomagania toczenia $\mathrm{w}$ zakresie prędkości skrawania $v_{c}=280-390 \mathrm{~m} / \mathrm{min}$ wraz $\mathrm{z}$ analizą wartości średnich prób (ANOM); (1) - wspomaganie sekwencyjne $G E=0,194 \mathrm{~J} / \mathrm{mm}^{2},(2)$ - wspomaganie sekwencyjne $G E=0,97$ $\mathrm{J} / \mathrm{mm}^{2},(3)$ - wspomaganie ciągłe $G E=0,194 \mathrm{~J} / \mathrm{mm}^{2}$

Fig. 4. Comparison of the $R z$ roughness parameter value after laser assisted turning in the cutting speed range $v_{c}=280-390 \mathrm{~m} / \mathrm{min}$ with an analysis of mean values (ANOM); (1) - sequential-assisted machining $G E=0.194 \mathrm{~J} / \mathrm{mm}^{2},(2)-$ sequential-assisted machining $G E=0.97$ $\mathrm{J} / \mathrm{mm}^{2}$, (3) - continuous-assisted machining $G E=0.194 \mathrm{~J} / \mathrm{mm}^{2}$

$v_{c}=280-350 \mathrm{~m} / \mathrm{min}$ dla wspomagania z małą gęstością mocy $G E$ rozrzut wyników jest najmniejszy - proces zachowuje stabilność. Powyżej $350 \mathrm{~m} / \mathrm{min}$ przy wspomaganiu sekwencyjnym następuje gwałtowny skok wartości odchylenia standardowego.

\section{Podsumowanie}

Przedstawiono metodykę doświadczalnego szacowania chropowatości powierzchni obrobionej dla zmiennych wartości prędkości skrawania przy różnych sposobach toczenia $\mathrm{w}$ warunkach wspomagania laserowego. Biorąc pod uwagę uzyskane wyniki, można sformułować następujące ogólne wnioski końcowe:

- optymalne ze względu na najmniejsze wartości parametrów amplitudowych chropowatości uzyskano dla stopu Inconel 718 po toczniu ze wspo- 
maganiem $\mathrm{w}$ trybie ciągłym (wspomaganie przez cieplne zmiękczenie warstwy skrawanej),

- każdy ze sposobów nagrzewania laserowego przed skrawaniem (SLAM) bądź w trakcie (CALM) skrawania pozwolił na uzyskanie mniejszych wartości parametrów chropowatości niż te, które uzyskuje się po procesie konwencjonalnym,

- zastosowanie wspomagania laserowego pozwala na wzrost wydajności procesu ubytkowego kształtowania przez zwiększenie prędkości skrawania powyżej zalecanej dla analizowanego materiału narzędziowego typu CBN.

Stanowi to podstawę do rozwinięcia zasadności ekonomicznego zastosowania technologii wspomaganych w przemyśle produkcyjnym.

\section{Podziękowania}

Prezentowane wyniki badań zostały sfinansowane ze środków Narodowego Centrum Badań i Rozwoju w ramach Programu Badań Stosowanych nr 244445.

\section{Literatura}

[1] Attia H., Tavakoli S., Vargas R., Thomson V.: Laser-assisted high-speed finish turning of superalloy Inconel 718 under dry conditions, CIRP Annals - Manuf. Technol., 59 (2010) 83-88.

[2] Burek J., Gulda M.: Geometria warstwy skrawanej w obróbce powierzchni złożonych frezem toroidalnym, Mechanik, 89 (2016) 1352-1352.

[3] Chwalczuk T., Kawalec M., Szablewski P.: Wybrane właściwości warstwy wierzchniej po toczeniu tradycyjnym i ukośnym ostrzami ceramicznymi nadstopu niklu Inconel 718 po nagrzewaniu laserowym, Mechanik, 85 (2012) 409-414.

[4] Grzesik W.: Możliwości prognozowania właściwości eksploatacyjnych części maszyn na podstawie cech topografii powierzchni, Mechanik, 88 (2015) 587-593.

[5] Lauwers B., Klocke F., Klink A., Tekkaya E.A., Neugebauer R., Mcintosh D.: Hybrid processes in manufacturing, CIRP Annals - Manuf. Technology, 63 (2014) 561-583.

[6] Mohsan A.U.H., Zhanqiang L., Padhy K.G.: A review on the progress towards improvement in surface integrity of Inconel 718 under high pressure and flood cooling conditions, Int. J. Adv. Manuf. Technol., 91 (2016) 423-428.

[7] Nelson P.R., Wludyka P.S., Copeland K.A.F.: Analysis of means: A graphical method for comparing means, rates, and proportions, ASA-SIAM Series on Statistics and Applied Probability, 2005.

[8] Parida A., Maity K.: Effect of nose radius on forces, and process parameters in hot machining of Inconel 718 using finite element analysis, Eng. Sci. Technol. Int. J., 20 (2017) 687-693.

[9] Przestacki D., Jankowiak M.: Surface roughness analysis after laser assisted machining of hard to cut materials, J. Physics: Conf. Series, No. 483 (2014): p. 012019. DOI: $10.1088 / 1742-6596 / 483 / 1 / 012019$. 
[10] Przestacki D., Chwalczuk T., Wojciechowski S.: The study on minimum uncut chip thickness and cutting forces during laser-assisted turning of $\mathrm{WC} / \mathrm{NiCr}$ clad layers, Int. J. Adv. Manuf. Technol., 02 (2017) DOI: 10.1007/s00170-017-0035-5.

[11] Venkatesan K.: The study on force, surface integrity, tool life and chip on laser assisted machining of Inconel 718 using Nd:YAG laser source, J. Adv. Research, 8 (2017) 407-423.

\section{FINISH TURNING OF INCONEL 718 WITH CBN INSERTS}

\section{S u m m a r y}

Presented research is focused on turning of Inconel 718 with CBN cutting inserts under conventional and laser assisted turning conditions. The influence of cutting speed on the values of selected parameters of surface roughness was shown. The optimization of technological parameters was carried out due to the minimization of the values of output parameters.

Keywords: turning, Inconel 718, CBN, surface roughness of machined surface

DOI: $10.7862 / \mathrm{rm} .2017 .26$

Otrzymano/received:12.07.2017

Zaakceptowano/accepted: 27.09.2017 